\title{
ADVERTISING STRATEGY ACCORDING TO THE CONCEPT OF THE FCB MODEL IN THE CONDITIONS OF THE VARIOUS GENERATIONS
}

\author{
Kateřina Matušínská1, Michal Stoklasa²
}

\begin{abstract}
1 Silesian University in Opava, School of Business Administration in Karviná, Department of Business Economics and Management, Czech Republic, ORCID: 0000-0002-0957-2860, matusinska@opf.slu.cz;

2 Silesian University in Opava, School of Business Administration in Karviná, Department of Business Economics and Management, Czech Republic, ORCID: 0000-0002-4968-7777, stoklasa@opf.slu.cz.
\end{abstract}

\begin{abstract}
The aims of the paper are: 1) to verify the validity of the traditional theoretical definition of the Foote, Cone \& Belding (FCB) model based on the use of representative products concerning the age (generation) and gender of the selected target group in the conditions of the Czech Republic, and 2) to verify the validity of defined advertising strategies in the traditional theoretical conception of the Foote, Cone \& Belding (FCB) model with the current level of acceptance and perception of advertising within the defined selected target group according to age (generation) and gender in the conditions of the Czech Republic. To meet both aims, both secondary and primary marketing research was implemented. The theoretical background of the paper is based on knowledge of marketing communication principles in general with emphasis on advertising theories. The greatest attention is focused on the traditional version of the FCB model which is based on a matrix of consumer thinking-feeling and high-low involvement behaviours and proposes four advertising strategies. Primary research data were obtained using a questionnaire, on the online panel of research agency Ipsos, on 1,100 Czech respondents. The methods used are positional maps for the FCB grid and chi-squared with a suitable post-hoc test. The outputs reveal the differences of the theoretical FCB model in comparison with its practical implementation. It is necessary to adapt (extend) the model according to specific conditions and identification features of different Czech generations and genders, then adjust recommendations for advertising strategies. In Czech conditions, the sextant grind should be used. There is a prevalence of representative product placement in quadrants 1 and 3, i.e., rational appeals even for products where this is not expected. The outcomes can be used for the choice of correct advertising strategy, advertising media, and types.
\end{abstract}

Keywords: Advertising, emotional and rational appeal, Foote, Cone \& Belding grid, involvement theory, marketing communication.

JEL Classification: M31, M37.

APA Style Citation: Matušínská, K., \& Stoklasa, M. (2021). Advertising Strategy According to the Concept of the FCB Model in the Conditions of the Various Generations. E\&M Economics and Management, 24(4), 189-205. https://doi.org/10.15240/tul/001/2021-4-012

\section{Introduction}

Integrated marketing communication is an arrangement by which organizations organize their online and offline marketing communication tools to provide a clear, consistent, trusted, and competitive message about an organization and its offer (Fahy \& Jobber, 2019). Organizations aim at attracting the target customers and communicating the value of the product (brand) to them clearly and convincingly (Kotler \& 
Armstrong, 2018). Modern communication technologies and approaches nowadays allow customers a much higher level of information availability, so potential and loyal customers regularly check the quality of all organizations and choose the best offers for themselves according to the recommendations of their acquaintances, friends, or discussion forums (Petrů et al., 2020). Despite the large increase in the use of personal communication due to Internet penetration, advertising in mixture with other marketing communication tools has a substantial impact on consumer interest, brand building, and sales. Advertising is considered a positive as well as a negative element in society (Copley, 2004). Advertising can be described as a form of social communication that works in many dimensions (Leiss et al., 2005). According to Blakeman (2018), advertising is known as a medium of mass media that can reach large and less targeted audiences.

The practical use of advertising is largely based on available theories from the field of psychology, sociology, anthropology, cybernetics, mathematics, communication science, and others (Hackley \& Hackley, 2018). Experts usually formulate and construct their work experience in their own words without using theoretical ideas but it does not mean that theory is not important to be implemented into practice (Hackley, 2000; Svenson, 2007). The theory provides a finer understanding of how different phenomena are interconnected, and theories can be seen as rules for setting a framework for policies and actions because it helps to guess outputs based on former experience or evidence-based assumptions (Hackley, 1999). Advertising is an area that is particularly concerned with theory, and theories are often applied as a basis through which individuals and interested organizations claim and negotiate a sense of professional identity (Case, 1999; Hackley, 2003a). Advertising (generally understood as a marketing communication itself) can be understood as an area of applied human science because it includes implicit predictions of how people will react to external stimuli in their behavior, even if actions are not explicitly based on theoretical assumptions, they are not there (Kover, 1995; Hackley, 2003b). It is necessary to argue about actions and strategies, apply them, explain them, test them and justify them, therefore the theory is a source of strength and serves to justify certain practices over alternatives (Burr, 1995; Berger \& Luckman, 1996; Billig, 1996).

Foote, Cone \& Belding (further as FCB) grid could be understood as one of the familiar theoretical models in the area of advertising planning strategies created by Vaughn (1980) which mixes knowledge from dissimilar sequential models and provides output in the form of four situations based on two scopes - involvement (small versus large interest) and thinking versus feeling. Even though this theoretical concept originated several decades ago current researchers still implement this theoretical framework in their different research studies to verify it or subsequently to adapt it to current market conditions. The selected recently published research articles including the FCB model issue can be appointed: 1) updating the Foote, Cone \& Belding grid (Cheong \& Cheong, 2020); 2) is the hierarchy dead or alive? (Valenti et al., 2020); 3) the interaction between rational arguments and emotional Appeals in the entrepreneurial pitch (Vázquez et al., 2019); 4) brand attribute associations, emotional consumer-brand Relationship and Evaluation of Brand Extensions (Pourazad et al., 2019); 5) Managerial Framework for brand advertising (Alt et al., 2019); 6) identify customer involvement during organic food purchase through FCB grid (Ghosh et al., 2018); 7) review of hierarchy-of effects (Hoe) models and higher education advertising in Malaysia (Yaakoop et al., 2018); 8) how to implement informational and emotional appeals in print advertisements (Teichert et al., 2018); 9) myths about the mind: time to end some popular beliefs about how advertising works (Ambler, 2015); 10) 'Thinking and Feeling' products and 'Utilitarian and Value-Expressive' appeals in contemporary TV advertising: a content analytic test of functional matching and the FCB model (Choi et al., 2010).

The authors of this article have already confirmed in the first phase of their research study that the theoretical framework of the FCB model has its limits and therefore there are opportunities to elaborate scientific research to update and modify it according to defined variables (Matušínská \& Zapletalová, 2021). The next stage of the research study brings other useful theoretical and practical findings which are presented in this article. The aims of the paper are: 1) to verify the validity of the 
traditional theoretical definition of the Foote, Cone \& Belding (FCB) model based on the use of representative products concerning the age (generation) and gender of the selected target group in the conditions of the Czech Republic; and 2) to verify the validity of defined advertising strategies in the traditional theoretical conception of the Foote, Cone \& Belding (FCB) model with the current level of acceptance and perception of advertising within the defined selected target group according to age (generation) and gender in the conditions of the Czech Republic.

\section{Literature Review}

\subsection{Advertising and Its Theoretical Background}

According to Levens (2012), advertising is a cost-effective, original method how to be in contact with groups of people, educate audiences about a product or brand. It can aware consumers of products that meet their needs, tell them when and where offers are available or suggest ways to compare competing brands. Dibb and Simking (2004) state that advertising is more expensive than other components of a marketing communication mix but due to a large number of viewers, listeners, or readers, the cost per capita is relatively low, certainly lower than personal selling or other forms of sales promotion. Another advantage of this marketing communication tool is that it includes the choice of mass media, which can target a very precisely defined target audience.

Advertising is constantly changing and there is a future for new forms of advertising such as contextual and behavioral advertising, location-based advertising, user-generated advertising, long-term advertising, short advertising, sponsored television, applications - new advertising, integrated mobile applications, applications, TV, and social television, postmodern advertising and creative advertising (Smith \& Zook, 2012). Vakratsas and Ambler (1999) suggest that advertising effects should be analyzed in a space with affect, cognition, and experience as three dimensions. Advertising positioning in this space should be determined by a context that reproduces the variety of the advertising goals, product category, competition, other aspects of the mix, product life cycle stage, and target market.
Advertising theory, both practical and academic public prefer verbalized or printed linguistic elements of promotional messages and underestimates essentials of communication that are implicit or unconscious (Heath \& Feldwick, 2008). Advertising is still often considered as a quasi-verbal message, which is consciously treated by individual recipients, who make a conscious and rational evaluation to compare consumption options (Hackley \& Hackley, 2018).

Cognitive information processing is a term that summarizes the enormous tradition of advertising theory. It includes not only the theory of communication but the implicit theory of human cognition. Ang (2014) states that cognitive information-processing models and their later concepts have many inferences for how execution tactics should be used in advertising. The use of communication models of information processing in advertising and related linear theories of persuasive communication also has several limits, because there is a presumption that advertising communication arises mainly in one direction to the passive receiver.

The Shannon-Weaver communication model as an information processing model was firstly designed to model the mathematical effectiveness of technical communication channels but was applied to mass communication. It is also known as the 'transmission' model because the data is transmitted to the receiver. It is linear in the sense that there is a direct line from sender to receiver and vice versa. There are many variants of the model, but its elementary parts are the same in most applications: sender, receiver, medium, the process of message decoding and encoding, communication noise, and feedback (Hackley \& Hackley, 2018).

Theories like AIDA (Attention-InterestDesire-Action) is a part of an essential theory of advertising because it is based on the premise that advertising is designed to persuade the receivers to change their behavior to buy a product (Hackley, 2009; Ajzen, 2002). Although this model is almost evidently an accurate outline of what happens, it is also very simplified (Blythe, 2003). According to Moriarty et al. (2019), there is another approach in the domain model that attempts to eliminate the idea of predictable linear steps. It is based on the idea that message has an impact on 
consumer reactions, not in steps, but at the same time. The three key effects or domains are determined in this approach: 1) awareness; 2) learning; 3 ) persuasion.

The theory of the hierarchy of effects represents the composition of probabilities because each stage of the process is a necessary assumption for the next stage (Percy et al., 2001). A quite modest explanation of how advertising works is demonstrated by the think-feel-do model (cognitive/affective/ conative component) developed in the 1970s. The cognitive component refers to the level of individuals' knowledge and belief about the product or beliefs about specific attributes of the offer. The affective component means the emotional state that is expressed about the product - good or bad, pleasant or unpleasant - the object is evaluated. The conative component is the action component of the attitude construct and refers to the character or aim of the individuals to behave in a certain way (Fill \& Turnbull, 2019). The idea is that advertising stimulates receivers to think about the message, feel about the brand, and then do something, such as try or buy. The think-feeldo scheme explains why many advertisements mix rationality with emotions. This statement is reinforced by a recent research study conducted by Gergely Nyilasy and Leonard Reid (in Moriarty et al., 2019), whose in-depth interviews found out that agency experts firmly believe that exposure to advertising causes variations in human cognition, emotions, and behavior - or think-feel-do. Pelsmacker et al. (2018) state that several scientists have subsequently designed alternative models. An example is the low-engagement effects hierarchy model, according to which individuals can buy a product after frequent exposure to marketing messages and then decide how they feel about it (cognitive/conative/affective hierarchy). Another possibility is an experiential hierarchy of effects model, in which the affective reaction of consumers to a product leads to its purchase, and if necessary, analyzes it later. This would specify an affective/conative/cognitive sequence. Kotler and Keller (2016) present four types of advertising strategies resulting from the individual phases of the Hierarchy-of-effects models as follows: 1) informative advertising, which aims to create brand awareness and knowledge of new products, new characteristics of current products; 2) persuasive advertising, aimed at creating kindness, preferences, beliefs and the purchase of a product; 3) a reminder of an advertisement aimed at stimulating the repurchase of products and services; 4) reinforcement advertising, which aims to convince current buyers that they have made the right choice.

Moriarty et al. (2019) represent their own Facets effects model, which is more complex than previous models explaining how advertising generates the effect in terms of dissimilar types of consumer responses. They suggest a six-factor model that is valuable both in setting goals and in evaluating the success of brand communication. Their response to the question of how brand communication works is that effective brand reporting produces six kinds of consumer responses: 1) awareness; 2) feel; 3) think/understand; 4) connect; 5) believe; and 6) act/do.

During the years of research and speculation, there is not a universal model that could be offered as the definitive explanation of marketing communication functioning. Based on currently available theoretical approaches and studies, it can be generally emphasized that communication messages must be aimed at the right audience, be comprehensible, relevant, and correct to the audience.

\subsection{FCB Model and Its Connection with Concepts of Advertising Strategies}

Vaughn (1980) proposed the combination of diverse sequence models and introduced a method known as the Foote, Cone \& Belding (FCB) grid (see Fig. 1). The FCB grid is usually designed as a quadrant or sporadically as a sextant in case, some products could belong to quadrant one and three or between quadrant 2 and 4 . The model is based on a matrix of consumer thinking versus feeling and low versus high involvement. The projected model categorizes four primary strategies for advertising planning and is based on comprehensive research in the field of traditional advertising theories, models of consumer behavior, theories of brain specialization, and consumer involvement in the decision-making process. Yssel (1996) examined in his research study the effectiveness of the FCB grid as a tool for the creation of advertising strategies. Advertising strategies developed according to various methodological approaches were analyzed and evaluated to demonstrate that 
the FCB grid leads to excellent advertising strategy outputs. According to Dube et al. (1996), advertising planning models such as the FCB grid propose that for products/brands where attitudes are based primarily on effect, the implementation of effective appeals in advertising is highly recommended. Conversely, if attitudes are primarily based on utilitarian, cognitive foundations, advertisers should use informative appeals.

The Foote, Cone \& Belding models upgraded the hierarchy-of-effects models by assuming that the cognitive/affective/conative sequence is not immutable. The terminology has been changed for the purpose of this model from cognitive/affective/conative to think-feeldo. The concept of the hierarchy-of-effects model coincides with the FCB model only within the defined quadrant 1 (Ang, 2014).

Purchasing decisions in the first quadrant are considered by a high degree of involvement and rational decision criteria. Firstly, the consumer requires to get knowledge about the product. The second quadrant includes purchasing decisions with a high degree of involvement but less information is needed. Here, the consumer wants to be emotionally attracted to the brand image, then gathers information and finally takes certain steps. There are purchasing decisions that require minimal cognitive effort and tend to be routine due to habit formation in the third quadrant. The fourth quadrant presents purchasing decisions that can be called 'little pleasure in life'. The predictable sequence of the purchasing decision steps is to buy a product, experience an affective response and then gather product knowledge (Pelsmacker et al., 2018).

Involvement within the involvement theory is understood that the concept largely refers to the personal relevance or importance to the consumer of a particular product or purchasing situation (Kimmel, 2018). According to Antilles (1984), involvement refers to the level of supposed personal significance and/or interest induced by the stimulus in a particular situation. According to Laurent and Kapferer (1985), the involvement is a function of the perceived risk of negative consequences (fear of error), social sanctions (fear of looking stupid or desire to

\section{Fig. 1: FCB grid and proposed advertising strategies}

\begin{tabular}{|c|c|c|}
\hline & $\begin{array}{l}\text { Think } \\
\text { 'Think products' motivate } \\
\text { consumers (customers) to buy due } \\
\text { to their objective, tangible and } \\
\text { functional characteristics. }\end{array}$ & $\begin{array}{l}\text { Feel } \\
\text { 'Feel products' are associated } \\
\text { with subjective, intangible, and } \\
\text { psychosocial characteristics. }\end{array}$ \\
\hline $\begin{array}{l}\text { High-involvement } \\
\text { Consumers are motivated to } \\
\text { engage in an extensive external } \\
\text { search when a purchase is high in }\end{array}$ & $\begin{array}{c}\text { Q1: Think } \rightarrow \text { Feel } \rightarrow \text { Do } \\
\text { Consumer: thinker - a rational } \\
\text { decision } \\
\text { Economical theory }\end{array}$ & $\begin{array}{l}\text { Q2: Feel } \rightarrow \text { Think } \rightarrow \text { Do } \\
\text { Consumer: feeler }- \text { a } \\
\text { psychological decision } \\
\text { Psychological theory }\end{array}$ \\
\hline $\begin{array}{c}\text { perceived risks which may be } \\
\text { functional, financial, social, or } \\
\text { personal in nature. }\end{array}$ & $\begin{array}{l}\text { Advertising strateg } \\
\text { informative }\end{array}$ & $\begin{array}{l}\text { Advertising strategy: } \\
\text { affective }\end{array}$ \\
\hline $\begin{array}{l}\text { Medium } \\
\text { (applied only in the case of the } \\
\text { sextant FCB grid concept) }\end{array}$ & $\begin{array}{l}\text { Q1 \& Q3: Think } \rightarrow \text { Do } \rightarrow \text { Feel } \\
\text { Consumer: thinking doer } \\
\text { Economical/responsive theories }\end{array}$ & $\begin{array}{l}\text { Q2 \& Q4: Feel } \rightarrow \text { Do } \rightarrow \text { Think } \\
\text { Consumer: impulsive feeler } \\
\text { Psychological/social theories }\end{array}$ \\
\hline $\begin{array}{l}\text { Low-involvement } \\
\text { Products that evoke low- } \\
\text { involvement processes are } \\
\text { frequently purchased, }\end{array}$ & $\begin{array}{c}\text { Q3: Do } \rightarrow \text { Think } \rightarrow \text { Feel } \\
\text { Consumer: doer - responsive } \\
\text { decision } \\
\text { Responsive theory }\end{array}$ & $\begin{array}{c}\text { Q4: Do } \rightarrow \text { Feel } \rightarrow \text { Think } \\
\text { Consumer: reactor - a social } \\
\text { decision } \\
\text { Social theory }\end{array}$ \\
\hline $\begin{array}{l}\text { inexpensive, and low in personal } \\
\text { relevance. }\end{array}$ & $\begin{array}{l}\text { Advertising strategy: } \\
\text { habit formation }\end{array}$ & $\begin{array}{l}\text { lertising strategy: } \\
\text { If-satisfaction }\end{array}$ \\
\hline
\end{tabular}

Source: modified according to Dickinger and Zon (2008); Yaakop et al. (2018); Josephson et al. (2020); Kimmel (2018); 
look good), and ego-relatedness (degree of adaptation with one's own image). Houston and Rothschild (1978) proposed four levels of involvement that induce either high or low involvement processes, as follows: 1) price; 2 ) length of the purchasing cycle; 3) similarity of choice; 4) perceived risks. In this sense, Rossiter et al. (1991) define the risk in terms of the possible undesirable consequences that the consumer notices when choosing a product or brand. High exposure happens when a consumer perceives an expected purchase that is not only of high personal meaning but also represents a high level of perceived risk. Consumers, therefore, dedicate a great deal of time to investigative these intended purchases and obtain as much information as possible to decrease the levels of perceived risk. A lowinvolvement state of mind proposes that the intended purchase poses a little threat or risk. Both of these situations require a different attitude in the case of marketing communication tools using. Hamzel et al. (2017) present their research results and state that customers with dissimilar levels of involvement react inversely to product failure. In addition, low-involvement products are more likely to advance silent killers. The results also show that a silent killer is more common among men.

The dimension of thinking and feeling is more problematic. It is recognized that the brain is in fact a unified system that integrates complex stimuli and deftly manages both information and emotions, but most of the discussion on this topic in the marketing literature has been metaphorical rather than empirical (Vaughn, 1986). An expert term in psychology for emotions and moods is 'affect', which is defined as a condition that includes experiential, expressive, and exciting components (Frijda, 1986; Gross, 1998). Cognition is a psychological term relating to thinking, which is a set of operations and processes by which a person gets knowledge about the world and himself based on past experiences, learning, expectations, and personal preferences (Kimmel, 2018). It is generally known that advertisers principally use rational or emotional persuasion strategies, while rational attraction is driven by the processing of information by the conscious mind, while emotional attraction is driven by the unconscious mind (Bhatia, 2019). Lee and Heere (2018) empirically examined the relative efficiency of emotional advertising over rational advertising and combined advertising. The results of their study show that emotional advertising has led to a higher approach to advertising, access to the brand, shopping intention, and consumption of goods than rational and combined advertising. It was also discovered that combined advertising led to a higher approach to advertising than to rational advertising. Hornik et al. (2016) argue that appeals against messages are a key part of communication campaigns and an important source of campaign influence. Based on their study, emotional attraction driven by sex and humor appears to be more effective than fear and rational attraction in advertising. Choi et al. (2010) confirm the fact that utilitarian challenges were used more in advertisements for think products, while value expressive appeals were used more in spots for feel products (studies in the field of television advertising using the FCB model).

\section{Research Methodology}

The data were obtained through a questionnaire survey conducted by the professional marketing research agency IPSOS in November 2020. The research sample consists of 1,100 respondents from the Czech Republic. The questionnaire was based on the theoretical framework of the Foote, Cone \& Belding model, meaning it was focused on purchasing process influenced by emotional and rational arguments and amount of effort. The first part of the questionnaire was focused on twelve representative product categories, the second part was focused on marketing communications, the third part on demographic characteristics of the respondents. The block about marketing communications deals with the preference of communication media and opinions about the advertisement type used.

Based on the underlying theoretical background and two main aims of the paper, three following research questions have been formulated:

RQ1: Is the original FCB model applicable regarding the use of representative products for Czech different generations and genders?

RQ2: What are the preferred advertising media regarding Czech different generations and genders?

RQ3: What are the preferred advertising types regarding Czech different generations and genders? 
The research process logic is as follows: based on the research questions, suitable methodology (tests) will be chosen, hypotheses will be formulated, results presented, and conclusions are drawn. For the first $R Q$, positional maps are used. For the second and third $R Q$, the variables used are categorical and nominal, and of two or more levels, therefore a suitable test is the chi-squared test. The test compares the observed values to the expected ones. The results will indicate if there is a statistically significant relationship between the two variables. Further, it needs to be tested which of the variables have what influence. This will be done through the post-hoc test. Adjusted standardized residuals and calculated adjusted $p$-values will be used. A residual is a difference in values observed and expected. If the adjusted residual exceeds the value of 1.96, it manifests 'the lack of fit to $H_{0}^{\prime}$ ' (Sharpe, 2015), meaning there is a statistically important difference. However, to account for Type 1 error, adjusted $p$-values have to be calculated through the right-tailed probability of the chisquared distribution. This process will reveal statistically significant results, meaning which media and advertisement types are recommended and not recommended for each combination of generations and genders (Shan \& Gerstenberger, 2017).

Working hypotheses are formulated for the areas of the $R Q 2$ and $R Q 3$ where statistical testing will be used, as follows:

$H_{1}$ : There is a dependence of media preference on selected demographic factors.

$\mathrm{H}_{2}$ : There is a dependence of advertisement type preference on selected demographic factors.

For the purpose of this article, the respondents were put into one of four generations based on their age. Generation Baby Boomers (born 1946-1965, further as Gen. BB) makes up $24.8 \%$ of the sample, Generation X (born 1966-1979, further as Gen. X) makes up 31.2\%, Generation Y (born 1980-1994, further as Gen. Y) makes up $31.2 \%$, and Generation Z/Teenagers Z (born 1995-2001, further as Gen. Z) makes up $12.8 \%$. The sample consists of $52.9 \%$ males (further as M., e.g., Gen. BB-M meaning males of Generation Baby Boomers) and $47.1 \%$ females (further as F, e.g. Gen Z-F).

\section{Research Results}

\subsection{Positional Maps for Representative Products}

To answer the RQ1, positional maps have been created. The maps contain twelve representative products in the FCB matrix. Fig. 2-4 show the results for each generation and gender. Looking at the results, we can see substantial differences across all generations and genders, and also with the underlying theoretical basis. Generally, we can comment that younger generations (especially Z) are inclining more to the feel products than older generations. Women across all generations also perceive products more as feel ones compared to men of the same generation. Home appliances (A), financial loans (B), and cars (C) differ only slightly in the think-feel dimension (average spread of 0.2 ) but have a great difference in the involvement dimension (a spread of 0.8 ), where younger generations ( $Z$ and $Y$ ) consider it as lower involvement. The location corresponds to the theoretical model. Jewellery $(D)$, food $(G)$, detergents $(H)$, and toiletries (I) differ the same in both dimensions (a spread of 0.4). Again, it can be said that the younger generations perceive it as lower involvement. Perfumes (E) and soft drinks (J) differ again the same in both dimensions (but with a spread of 0.5 ), and alcoholic beverages (K) (but with a spread of 0.6). Women consider perfumes more as a feel product across all generations, but we can also observe much lower involvement for men of older generations (BB and $\mathrm{X}$ ). Women consider alcoholic beverages as lower involvement. Clothes (F) and sweets $(L)$ differ greatly in the think-feel dimension (a spread of 0.6 ) but very little in the involvement dimension (a spread of 0.2). Men consider sweets as more think product. Women of younger generations consider clothes more as a feel product.

The main outcomes are as follows: only the positioning of representative products $A, B$, and $C$ corresponds to the positioning according to the FCB model and a subsequent sequence of think-feel-do decision phases can be assumed based on the effect of the advertising message (hierarchy of effects theory). We can see the prevalence of representative product placement especially in quadrants 1 and 3, i.e., rational appeals even for products where it is not expected. All of this leads to the confirmation of the FCB model application in the form of the 


\section{Marketing and Trade}

\section{Fig. 2: Generation Baby Boomers - male versus female}

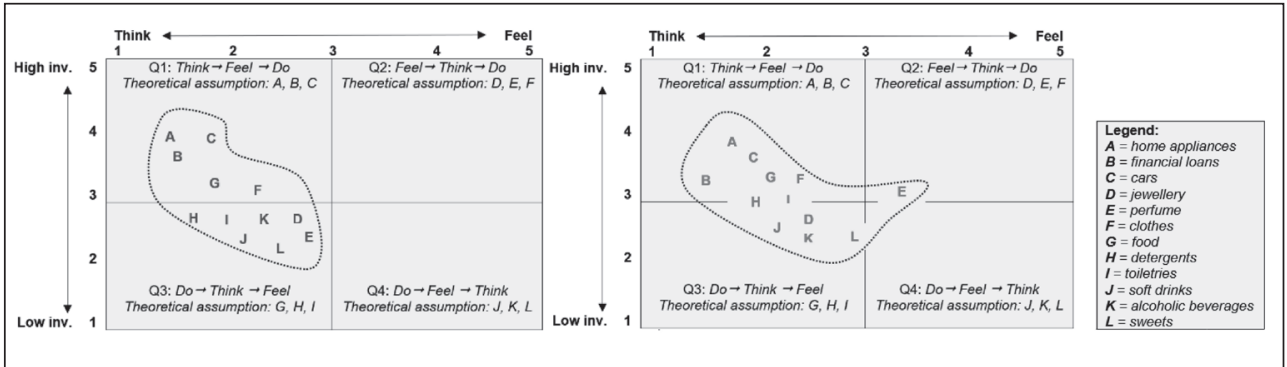

Source: own

\section{Fig. 3: Generation $\mathbf{X}-$ male versus female}

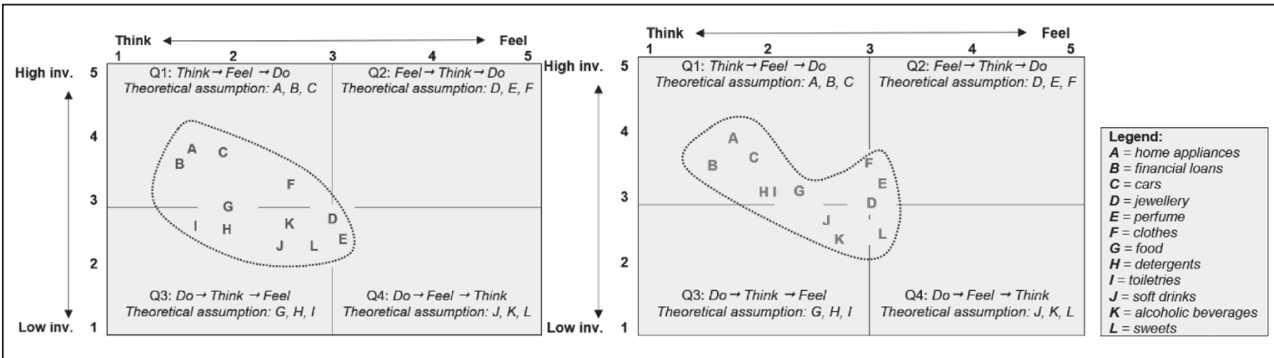

Source: own

\section{Fig. 4: Generation Y - male versus female}

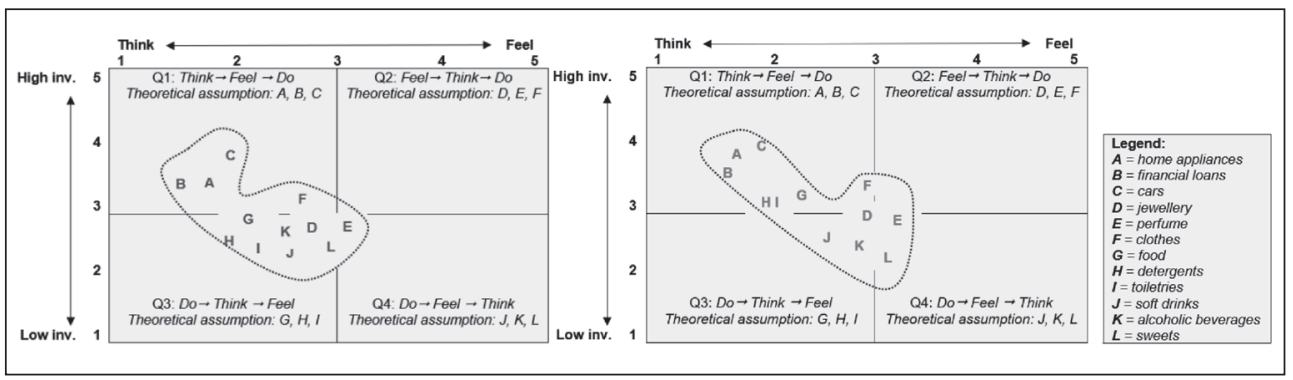

Source: own 


\section{Fig. 5: Generation Z/Teenagers Z - male versus female}

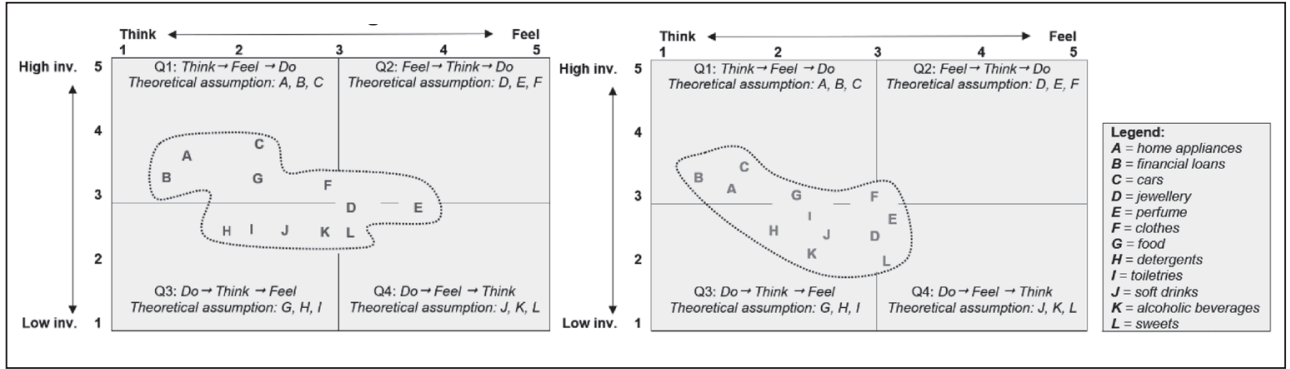

Source: own

sextant grid for all generations and genders studied. We can conclude as an answer to the $R Q 1$ that the traditional FCB model should not be used as is but rather should be expanded into the sextant grid and adapted to the different target audiences. Based on the facts found above, it is also necessary to pay attention to the individual defined four model advertising strategies (see Discussion).

\subsection{Summarized Data for Preferred Advertising Medium and Type}

To answer the $R Q 2$ and $R Q 3$, the data is presented for the preferred advertisement medium and type. Tab. 1 shows the preferred advertisement medium for each combination of generation and gender. The data is recalculated as relative for each column to show the preference of each medium. The most preferred medium across all genders and generations is TV advertisement, followed by Leaflets and the Internet. However, we can observe the differences between generations on the preference of internet and social media advertisement, with younger generations favouring it more. The opposite trend for instore advertisement and leaflets being preferred more by older generations.

\section{Tab. 1: Preferred medium for each generation and gender (relative for each column, in \%)}

\begin{tabular}{l|c|c|c|c|c|c|c|c}
\multicolumn{1}{c|}{ Medium type } & Gen. BB-M & Gen. BB-F & Gen. X-M & Gen. X-F & Gen. Y-M & Gen. Y-F & Gen. Z-M & Gen. Z-F \\
\hline TV ad. & 34.4 & 30.3 & 30.9 & 35.5 & 30.0 & 39.9 & 30.1 & 25.9 \\
\hline Internet ad. & 7.3 & 8.2 & 19.1 & 11.6 & 24.4 & 19.7 & 19.3 & 15.5 \\
\hline Social media ad. & 3.3 & 4.1 & 2.7 & 4.5 & 9.4 & 8.7 & 15.7 & 25.9 \\
\hline $\begin{array}{l}\text { E-mail, commercial } \\
\text { SMS/MMS }\end{array}$ & 7.3 & 2.5 & 4.8 & 3.2 & 5.0 & 1.1 & 3.6 & 5.2 \\
\hline In-store ad. & 15.2 & 10.7 & 11.2 & 13.5 & 13.1 & 7.7 & 9.6 & 8.6 \\
\hline Leaflets & 25.2 & 38.5 & 21.8 & 22.6 & 12.5 & 16.9 & 9.6 & 10.3 \\
\hline Billboards, posters & 1.3 & 1.6 & 0.5 & 2.6 & 0.0 & 2.2 & 3.6 & 0.0 \\
\hline Vehicles ad. & 0.7 & 0.0 & 2.7 & 2.6 & 1.3 & 0.5 & 1.2 & 0.0 \\
\hline Print ad. & 2.0 & 4.1 & 3.2 & 1.3 & 1.9 & 0.5 & 1.2 & 3.4 \\
\hline Radio ad. & 1.3 & 0.0 & 2.1 & 1.9 & 2.5 & 2.2 & 3.6 & 5.2 \\
\hline Cinema ad. & 2.0 & 0.0 & 1.1 & 0.6 & 0.0 & 0.5 & 2.4 & 0.0 \\
\hline
\end{tabular}


Tab. 2: Preferred ad. type for each generation and gender (relative for each column, in \%)

\begin{tabular}{l|c|c|c|c|c|c|c|c}
\multicolumn{1}{c|}{ Advertisement type } & Gen. BB-M & Gen. BB-F & Gen. X-M & Gen. X-F & Gen. Y-M & Gen. Y-F & Gen. Z-M & Gen. Z-F \\
\hline Celebrity & 5.3 & 3.3 & 3.7 & 6.5 & 7.5 & 9.3 & 15.7 & 12.1 \\
\hline Humour & 49.0 & 40.2 & 46.8 & 42.6 & 36.3 & 38.3 & 34.9 & 24.1 \\
\hline Melody & 7.3 & 9.8 & 6.4 & 7.1 & 4.4 & 9.3 & 6.0 & 12.1 \\
\hline Warmth, love & 6.6 & 11.5 & 6.4 & 8.4 & 2.5 & 9.3 & 6.0 & 5.2 \\
\hline Expert & 17.2 & 13.1 & 16.0 & 16.8 & 26.3 & 9.8 & 14.5 & 19.0 \\
\hline Animal & 3.3 & 14.8 & 7.4 & 12.3 & 7.5 & 10.9 & 6.0 & 22.4 \\
\hline Erotic & 6.0 & 0.0 & 9.0 & 0.6 & 9.4 & 1.1 & 12.0 & 1.7 \\
\hline Animated, mascots & 2.0 & 1.6 & 1.1 & 0.6 & 2.5 & 3.8 & 2.4 & 1.7 \\
\hline Children & 2.6 & 5.7 & 2.7 & 5.2 & 1.9 & 7.7 & 2.4 & 1.7 \\
\hline Fear & 0.7 & 0.0 & 0.5 & 0.0 & 1.9 & 0.5 & 0.0 & 0.0 \\
\hline
\end{tabular}

Source: own

Tab. 2 shows the preferred advertisement type for each combination of generation and gender. The data is recalculated as relative for each column to show the preference of each advertisement type. The most preferred ad. type across all generations and genders is a humorous ad. All other types show bigger differences amongst generations and/or genders. For example, celebrities are more preferred with younger generations, animals are more preferred by females, erotic emotions by males.

\subsection{Statistical Testing}

The data needs to be transformed first to be usable in the chosen chi-squared test. Certain categories have low amounts of responses and are therefore not suitable for testing. These categories are merged based on their affinity. The data are also filtered according to generation and gender.

For media preference, all printed types of advertisement are merged (billboards, posters, print, vehicles) into a new category called a print. Cinema advertisement is joined into TV. And radio advertisement is deleted as it has a minuscule amount of preferences (23) and no affinity to any other category. Out of the 11 original categories, 7 remain for testing.

Working hypothesis 1 is transformed into statistical:

$H_{0}$ : Media preference does not depend on generation and gender.

$H_{1}$ : Media preference depends on generation and gender.
The results of the test of independence of media preference on generation and gender are as follows. Value sig. 0.000 is less than the chosen significance level value, the variables are related. The test criterion is 146.893 and therefore does not fall within the scope of acceptance, at the level of significance $5 \% H_{0}$ about the independence of individual characters is rejected and we accept the alternative hypothesis $H_{1}$ that there is a certain dependence. Therefore: the dependence of the media preference on generation and gender is statistically significant.

The further post-hoc test will reveal details, which media preference is significant for which generation and gender. Adjusted residuals and calculated adjusted p-values are used, see results in Tab. 3. The value of adjusted residual over 1.96 signifies a statistically important result, with minus being negative and plus being a positive relationship. It can be stated that almost all the media have one or more statistically significant results, in this case meaning (not) preferred, to some of the generations and genders. The data from Tab. 3 and the following discussion answer RQ2.

For advertisement type preference, only categories animated figures, mascots, and children are merged creating one new category called mascots. Fear has a minuscule amount of preferences (6) and is deleted. Out of the 10 original categories, 8 remain for testing. 


\begin{tabular}{|c|c|c|c|c|c|c|c|c|c|}
\hline Medium & Statistics & Gen. BB-M & Gen. BB-F & Gen. X-M & Gen. X-F & Gen. Y-M & Gen. Y-F & Gen. Z-M & Gen. Z-F \\
\hline \multirow{4}{*}{ TV ad. } & Count & 57 & 37 & 64 & 59 & 54 & 76 & 15 & 10 \\
\hline & Expected count & 52.2 & 42.1 & 64.9 & 53.5 & 56 & 62.5 & 23.5 & 17.3 \\
\hline & Adj. residual & 0.9 & -1 & -0.2 & 1 & -0.4 & 2.3 & -2.2 & -2.2 \\
\hline & Adj. p-value & 0.3681 & 0.3173 & 0.8415 & 0.3173 & 0.6892 & 0.0214 & 0.0278 & 0.0278 \\
\hline \multirow{4}{*}{ Internet } & Count & 11 & 10 & 36 & 18 & 39 & 36 & 16 & 9 \\
\hline & Expected count & 24.5 & 19.8 & 30.5 & 25.2 & 26.3 & 29.4 & 11 & 8.1 \\
\hline & Adj. residual & -3.2 & -2.6 & 1.2 & -1.7 & 2.9 & 1.5 & 1.7 & 0.3 \\
\hline & Adj. p-value & 0.0014 & 0.0093 & 0.2301 & 0.0891 & 0.0037 & 0.1336 & 0.0891 & 0.7642 \\
\hline \multirow{4}{*}{$\begin{array}{l}\text { Social } \\
\text { media }\end{array}$} & Count & 5 & 5 & 5 & 7 & 15 & 16 & 13 & 15 \\
\hline & Expected count & 11.4 & 9.2 & 14.1 & 11.7 & 12.2 & 13.6 & 5.1 & 3.8 \\
\hline & Adj. residual & -2.1 & -1.5 & -2.8 & -1.5 & 0.9 & 0.7 & 3.7 & 6.2 \\
\hline & Adj. p-value & 0.0357 & 0.1336 & 0.0051 & 0.1336 & 0.3681 & 0.4839 & 0.0002 & 0.0000 \\
\hline \multirow{4}{*}{ E-mail } & Count & 11 & 3 & 9 & 5 & 8 & 2 & 3 & 3 \\
\hline & Expected count & 6.2 & 5 & 7.7 & 6.3 & 6.6 & 7.4 & 2.8 & 2 \\
\hline & Adj. residual & 2.1 & -1 & 0.5 & -0.6 & 0.6 & -2.2 & 0.1 & 0.7 \\
\hline & Adj. p-value & 0.0357 & 0.3173 & 0.6171 & 0.5485 & 0.5485 & 0.0278 & 0.9203 & 0.4839 \\
\hline \multirow{4}{*}{ In-store } & Count & 23 & 13 & 21 & 21 & 21 & 14 & 8 & 5 \\
\hline & Expected count & 17.7 & 14.3 & 22 & 18.1 & 19 & 21.2 & 8 & 5.8 \\
\hline & Adj. residual & 1.5 & -0.4 & -0.2 & 0.8 & 0.5 & -1.8 & 0 & -0.4 \\
\hline & Adj. p-value & 0.1336 & 0.6892 & 0.8415 & 0.4237 & 0.6171 & 0.0719 & 1.0000 & 0.6892 \\
\hline \multirow{4}{*}{ Leaflets } & Count & 38 & 47 & 41 & 35 & 20 & 31 & 8 & 6 \\
\hline & Expected count & 31.7 & 25.6 & 39.5 & 32.5 & 34 & 38 & 14.3 & 10.5 \\
\hline & Adj. residual & 1.4 & 5.1 & 0.3 & 0.5 & -2.9 & -1.4 & -1.9 & -1.6 \\
\hline & Adj. p-value & 0.1615 & 0.0000 & 0.7642 & 0.6171 & 0.0037 & 0.1615 & 0.0574 & 0.1096 \\
\hline \multirow{4}{*}{ Print } & Count & 6 & 7 & 12 & 10 & 5 & 6 & 5 & 2 \\
\hline & Expected count & 7.4 & 6 & 9.3 & 7.6 & 8 & 8.9 & 3.3 & 2.5 \\
\hline & Adj. residual & -0.6 & 0.4 & 1 & 1 & -1.2 & -1.1 & 1 & -0.3 \\
\hline & Adj. p-value & 0.5485 & 0.6892 & 0.3173 & 0.3173 & 0.2301 & 0.2713 & 0.3173 & 0.7642 \\
\hline
\end{tabular}

Working hypothesis 2 is transformed into statistical:

$H_{0}$ : Advertisement type preference does not depend on generation and gender.

$H_{1}$ : Advertisement type preference depends on generation and gender.

The results of the test of independence of advertisement type preference on generation and gender are as follows. Value sig. 0.000 is less than the chosen significance level value, the variables are related. The test criterion is 130.284 and therefore does not fall within the scope of acceptance, at the level of significance $5 \% H_{0}$ about the independence of individual characters is rejected and we accept the alternative $H_{1}$ that there is a certain dependence. Therefore: The dependence of the advertisement type preference on generation and gender is statistically significant.

The further post-hoc test will reveal details, which advertisement type preference 


\section{Tab. 4: Crosstabulation results for advertisement type on generation and gender}

\begin{tabular}{|c|c|c|c|c|c|c|c|c|c|}
\hline Ad. type & Statistics & Gen. BB-M & Gen. BB-F & Gen. X-M & Gen. X-F & Gen. Y-M & Gen. Y-F & Gen. Z-M & Gen. Z-F \\
\hline \multirow{4}{*}{ Celebrity } & Count & 9 & 4 & 6 & 12 & 17 & 16 & 8 & 6 \\
\hline & Expected count & 10.8 & 8.7 & 13.3 & 11.2 & 11.6 & 12.9 & 5.6 & 4.1 \\
\hline & Adj. residual & -0.6 & -1.8 & -2.3 & 0.3 & 1.8 & 1 & 1.1 & 1 \\
\hline & Adj. p-value & 0.5485 & 0.0719 & 0.0214 & 0.7642 & 0.0719 & 0.3173 & 0.2713 & 0.3173 \\
\hline \multirow{4}{*}{ Humour } & Count & 74 & 49 & 88 & 66 & 58 & 70 & 29 & 14 \\
\hline & Expected count & 61.8 & 50 & 76.2 & 64.3 & 66.3 & 74.1 & 31.9 & 23.3 \\
\hline & Adj. residual & 2.2 & -0.2 & 1.9 & 0.3 & -1.4 & -0.7 & -0.7 & -2.6 \\
\hline & Adj. p-value & 0.0278 & 0.8415 & 0.0574 & 0.7642 & 0.1615 & 0.4839 & 0.4839 & 0.0093 \\
\hline \multirow{4}{*}{ Melody } & Count & 11 & 12 & 12 & 11 & 7 & 17 & 5 & 7 \\
\hline & Expected count & 11.3 & 9.1 & 13.9 & 11.8 & 12.1 & 13.6 & 5.8 & 4.3 \\
\hline & Adj. residual & -0.1 & 1 & -0.6 & -0.3 & -1.7 & 1.1 & -0.4 & 1.4 \\
\hline & Adj. p-value & 0.9203 & 0.3173 & 0.5485 & 0.7642 & 0.0891 & 0.2713 & 0.6892 & 0.1615 \\
\hline \multirow{4}{*}{$\begin{array}{l}\text { Warmth, } \\
\text { love }\end{array}$} & Count & 10 & 14 & 12 & 13 & 4 & 17 & 5 & 3 \\
\hline & Expected count & 10.8 & 8.7 & 13.3 & 11.2 & 11.6 & 12.9 & 5.6 & 4.1 \\
\hline & Adj. residual & -0.3 & 2 & -0.4 & 0.6 & -2.5 & 1.3 & -0.3 & -0.6 \\
\hline & Adj. p-value & 0.7642 & 0.0455 & 0.6892 & 0.5485 & 0.0124 & 0.1936 & 0.7642 & 0.5485 \\
\hline \multirow{4}{*}{ Expert } & Count & 26 & 16 & 30 & 26 & 42 & 18 & 12 & 11 \\
\hline & Expected count & 25 & 20.2 & 30.8 & 26 & 26.8 & 29.9 & 12.9 & 9.4 \\
\hline & Adj. residual & 0.2 & -1.1 & -0.2 & 0 & 3.5 & -2.6 & -0.3 & 0.6 \\
\hline & Adj. p-value & 0.8415 & 0.2713 & 0.8415 & 1.0000 & 0.0005 & 0.0093 & 0.7642 & 0.5485 \\
\hline \multirow{4}{*}{ Animal } & Count & 5 & 18 & 14 & 19 & 12 & 20 & 5 & 13 \\
\hline & Expected count & 14.6 & 11.8 & 18 & 15.2 & 15.7 & 17.5 & 7.6 & 5.5 \\
\hline & Adj. residual & -2.9 & 2 & -1.1 & 1.1 & -1.1 & 0.7 & -1 & 3.4 \\
\hline & Adj. p-value & 0.0037 & 0.0455 & 0.2713 & 0.2713 & 0.2713 & 0.4839 & 0.3173 & 0.0007 \\
\hline \multirow{4}{*}{ Erotic } & Count & 9 & 0 & 17 & 1 & 15 & 2 & 10 & 1 \\
\hline & Expected count & 7.6 & 6.1 & 9.4 & 7.9 & 8.1 & 9.1 & 3.9 & 2.9 \\
\hline & Adj. residual & 0.6 & -2.7 & 2.8 & -2.7 & 2.7 & -2.6 & 3.3 & -1.2 \\
\hline & Adj. p-value & 0.5485 & 0.0069 & 0.0051 & 0.0069 & 0.0069 & 0.0093 & 0.0010 & 0.2301 \\
\hline \multirow{4}{*}{ Mascots } & Count & 7 & 9 & 7 & 9 & 7 & 21 & 4 & 2 \\
\hline & Expected count & 9.1 & 7.4 & 11.2 & 9.5 & 9.8 & 10.9 & 4.7 & 3.4 \\
\hline & Adj. residual & -0.8 & 0.7 & -1.4 & -0.2 & -1 & 3.4 & -0.3 & -0.8 \\
\hline & Adj. p-value & 0.4237 & 0.4839 & 0.1615 & 0.8415 & 0.3173 & 0.0007 & 0.7642 & 0.4237 \\
\hline
\end{tabular}


is significant for which generation and gender. Adjusted residuals and calculated adjusted $p$ values are used, see results in Tab. 4. The value of adjusted residual over 1.96 signifies a statistically important result, with minus being negative and plus being a positive relationship. It can be stated that almost all the advertisement types have one or more statistically significant results, in this case meaning (not) preferred, to some of the generations and genders. The data from Tab. 4 and the following discussion answer the $R Q 3$.

\section{Discussion}

Based on the research data, company managers should choose an appropriate FCB advertising strategy for their target audience, a preferred advertising medium, and type.

Informative advertising strategy (Q1) or the use of rational appeals with the provision of sufficient information sources about the product. The individual goes through the stages of reaction to advertising in a sequence: think-feel-do. The advertising cannot induce immediate action but rather a series of mental effects must occur. Based on the theoretical definition, the representative products 'home appliances', 'financial loans', and 'cars' should belong here. Our study confirms this assumption for this quadrant for all generations and both genders. From a general point of view, products 'food', 'clothes', 'detergents', and 'toiletries' also tend to belong to Q1. According to the theoretical assumptions, products 'food', 'detergents', and 'toiletries' should belong to Q3 with a defined advertising strategy called Habit formation, and 'clothes' should belong to Q2 with an Affective advertising strategy. For these anomalies, however, the research results for the different generations and genders must be considered. For the Gen. BB-M, the representative products 'food' and 'clothes' fall into this quadrant. For the Gen. BB-F, the 'clothes', 'food', 'detergents' and 'toiletries' all belong to Q1, with some on the edge to Q3. For the Gen. X-M, the 'clothes' and 'food' categories are positioned in the Q1, with 'clothes' on the edge of Q3. For Gen. X-F, products 'clothes', 'food', 'detergents', and 'toiletries' belong to this quadrant, again with 'clothes' on the edge of Q3. For Gen. Y-M, product 'clothes' belongs to this quadrant, and product 'food' is on the border of Q1 and Q3. For Gen. Y-F, the product 'clothes', 'food', 'detergents', and 'toiletries' also belong to Q1. In terms of Gen. Z-M, products 'food' and 'clothes' are in Q1. For Gen. Z-F, products 'food' and 'clothes' can be classified in Q1 and Q3.

Affective advertising strategy (Q2) or the use of emotional appeals with the provision of sufficient information sources about the product. The individual goes through successive phases of reaction to advertising in the sequence: feelthink-do. Based on the theoretical definition, representative products 'jewellery', 'perfume', and 'clothes' should belong here. Significant differences can be seen in this quadrant compared to the theoretical assumption that emotional appeals play a large role here, as rational arguments are also expected in the communication message. The representative products shift significantly to Q1 or Q3, here it depends on the specific generation and gender, but it can be noted that the outcomes for the different groups studied are very similar. Overall, of the three representative products, the product category 'perfume' is most closely associated with emotional appeals.

Habit formation advertising strategy (Q3) or the use of rational appeals with less demand for information sources about the product. The individual goes through the stages of reaction to advertising in the sequence: do-thinkfeel. Based on the theoretical definition, the representative products 'food', 'detergents', and 'toiletries' should belong here. No significant differences can be seen in this quadrant compared to the theoretical assumption, as expected, rational arguments play a significant role here. There is an increasing tendency to seek information and to be involved in the actual purchase decision process. Again, the representative products are mainly located on the borderline between Q1 and Q3. The results for the different groups studied are very similar. Overall, of the three representative products, the 'food' category in particular shows a greater involvement of individuals in the purchase decision-making process.

Self-satisfaction advertising strategy (Q4) or the use of emotional appeals with less demand for information sources about the product. The individual goes through the phases of reaction to advertising in a sequence: dofeel-think. Based on the theoretical definition, representative products 'soft drinks', 'alcoholic beverages', and 'sweets' should belong here. A very interesting fact can be noted here, all representative products have moved into Q3, 
where individuals expect rational arguments. Of the representative products, the product category 'sweets' is the most useful for the use of emotional appeals in advertising messages. Significant differences within the target groups studied cannot be indicated.

The majority of representative products within the position maps are located on the border of two quadrants (especially quadrants 1 and 2). In this case, it is desirable to use the concept of the FCB grid, which does not consist of only four quadrants but six quadrants. The sextant grid offers advantages mainly in greater flexibility in creating more targeted advertising strategies. There are two new quadrants that expand the possibilities of intensity (high, medium, and low) involvement of the individual as the reaction to the advertising. The rational and emotional level remains (think versus feel products). Within the medium involvement/ rational appeals $(\mathrm{Q} 1 \&$ \&3) the individual goes through successive phases of reaction to advertising in the sequence: think-do-feel. For this situation, the advertising strategy can be called 'responsible'. Based on our research, product categories such as 'food', 'detergents' and 'toiletries' can be identified. In contrast, the individual goes through successive phases of reaction to advertising in the sequence: feel-dothink in medium involvement/emotional appeals quadrant (Q2 \& Q4). For this situation, the advertising strategy can be called 'pleasuring'. Here, the examples of individual product categories are not entirely clear. As stated above, several representative product categories theoretically falling into emotional appeals have moved into the field of rational appeals.

Considering the research results for the preferred advertising medium, the following recommendations can be made. It is recommended to use TV advertisement for Gen. Y-F, and not use it to target both Gen. Z-M and $F$. It is not recommended to use Internet advertisement for Gen. BB-M, and for Gen. BB-F and Gen. X-F, while it is recommended for Gen. Y-M. It is not recommended to use social media advertisement for Gen. BB-M and Gen. X-M, while it is strongly recommended for both genders of Gen. Z. E-mails or commercial SMS/MMS texts are recommended for Gen. BB-M, while not recommended for Gen. Y-F. Leaflets are strongly recommended for Gen. BB-F, while not recommended for Gen. Y-M.
Considering the research results for preferred advertising types, the following recommendations can be made. It is not recommended to use celebrities in the advertisement for Gen. X-M. It is recommended to use humour in the advertisement for Gen. BB-M and Gen. X-M, while it is not recommended for Gen. Z-F. Warmth and love are recommended for Gen. BB-F, while not recommended for Gen. Y-M. The use of experts in the advertisement is recommended for Gen. Y-M, while not recommended for Gen. Y-F. The use of animals is recommended for Gen BB-F and Gen. Z-F, while not recommended for Gen BB-M. The use of erotic emotions in the advertisement resonated the most, where it is recommended for almost all males of all generations and not recommended for all females of all generations. And finally, the use of mascots is recommended for Gen. Y-F.

\section{Conclusions}

The aims of the paper are: 1) to verify the validity of the traditional theoretical definition of the Foote, Cone \& Belding (FCB) model based on the use of representative products concerning the age (generation) and gender of the selected target group in the conditions of the Czech Republic; and 2) to verify the validity of defined advertising strategies in the traditional theoretical conception of the Foote, Cone \& Belding (FCB) model with the current level of acceptance and perception of advertising within the defined selected target group according to age (generation) and gender in the conditions of the Czech republic. The data were gathered in November 2020 through research agency Ipsos on a panel of 1,100 respondents from the Czech Republic. The respondents were divided into four generations and two genders.

For the first aim, 8 positional maps (4 generations and 2 genders) of 12 representative products were created. Considerable differences between the theoretical FCB model and reality were found. It is necessary to adapt and extend the model according to specific conditions and identification features of target groups. Only the positioning of representative products 'home appliances', 'financial loans', and 'cars' corresponds to the positioning according to the FCB model and it can be assumed that there is a gradual sequence of decision phases of thinkfeel-do based on the effect of the advertising message (theory of hierarchy of effects). The 
remaining 9 product categories are all different from the theoretical model, leading to the use of different advertising strategies in the Czech Republic. Due to the close link between the first and third quadrant, the adapted sextant grid should be used.

For the second aim, the data were tested with chi-squared and a suitable post-hoc test. It was found that the dependence of the media preference, and also advertisement type, on generation and gender are statistically significant. The post-hoc test revealed what advertisement media and type are most and least suitable for what generation and gender.

Based on their target audience, marketing managers can use the outcomes of this paper to choose the correct advertising strategy, advertising medium, and type.

Acknowledgments: "This paper was supported by the Ministry of Education, Youth and Sports Czech Republic within the Institutional Support for Long-term Development of a Research Organization in 2021".

\section{References}

Ajzen, I. (2002). Perceived Behavioural Control, Self-efficacy, Locus of Control, and the Theory of Planned Behaviour. Journal of Applied Social Psychology, 32(4), 665-683. https://doi. org/10.1111/j.1559-1816.2002.tb00236.x

Alt, M. A., Săplăcan, Z., \& Berács, J. (2019). Managerial Framework for Bank Advertising. International Journal of Bank Marketing, 37(7), 1547-1565. https://doi.org/10.1108/IJBM-102018-0288

Ambler, T. (2015). Myths about the mind: Time to end some popular beliefs about how advertising works. International Journal of Advertising, 17(4), 501-509. https://doi.org/10 .1080/02650487.1998.11104735

Ang, L. (2014). Principles of Integrated Marketing Communications. Cambridge: Cambridge University Press.

Antiles, J. (1984). Conceptualization and Operationalization of Involvement. Advances in Consumer Research, 11(1), 203-209.

Berger, P. L., \& Luckman, T. (1996). The Social Construction of Reality. London: Penguin.

Bhatia, T. K. (2019). Emotions and Language in Advertising. World Englishes, 38(3), 435449. https://doi.org/10.1111/weng.12420
Billig, M. (1996). Arguing and Thinking: A Rhetorical Approach to Social Psychology. Cambridge: Cambridge University Press.

Blakeman, R. (2018). Integrated Marketing Communication: Creative Strategy from Idea to Implementation. London: Rowman \& Littlefield.

Blythe, J. (2003). Essentials of Marketing Communications. Harlow: Pearson Education.

Burr, V. (1995). An Introduction to Social Constructionism. London: Routledge.

Case, P. (1999). Remember Reengineering? The Rhetorical Appeal of a Managerial Salvation Device. Journal of Management Studies, 36(4), 419-441. https:// doi.org/10.1111/1467-6486.00143

Cheong, H. J., \& Cheong, Y. (2020). Updating the Foote, Cone \& Belding Grid: Revisiting the Product Classifications Of the FCB Grid for Online Shopping And Contemporary Consumers' Decision Making. Journal of Advertising Research, 61(1), 12-29. https://doi.org/10.2501/JAR-2020-014

Choi, H., Yoon, H. J., Paek, H., \& Reid, L. N. (2010). 'Thinking and feeling' products and 'utilitarian and value-expressive' appeals in contemporary TV advertising: A content analytic test of functional matching and the FCB model. Journal of Marketing Communications, 18(2), 91-111. https://doi.org/10.1080/13527266.201 0.484581

Claeys, C., Swinnen, A., \& Abeele, P. V. (1995). Consumer's means-end chains for "think" and "feel" products. International Journal of Research in Marketing, 12(3), 193-208. https://doi.org/10.1016/0167-8116(95)00021-S

Copley, P. (2004). Marketing Communications Management: Concepts, Theories, Cases and Practices. Oxford: Butterworth-Heinemann.

Dib, S., \& Simkin, S. (2004). Marketing Briefs: A Revision and Study Guide. Oxford: Butterworth-Heinemann.

Dickinger, A., \& Zorn, S. (2008). Compensation Models for Interactive Advertising. Journal of Universal Computer Science, 14(4), 557-565.

Dube, L., Chattopadhyay, A., \& Letarte, A. (1996). Should Advertising Appeals Match the Basis of Consumers' Attitudes? Journal of Advertising Research, 36(6), 82-89.

Fahy, J., \& Jobber, D. (2019). Foundations of Marketing (6th ed.). London: McGraw-Hill Education.

Fill, C., \& Turnbull, S. (2019). Marketing Communications: Touchpoints, Sharing and Disruption. Harlow: Pearson Education. 
Frijda, N. H. (1986). The Emotions. Cambridge: Cambridge University Press.

Ghosh, S., Barai, P., \& Datta, B., (2018). Identify Customer Involvement During Organic Food Purchase Through FCB Grid. Journal of International Food \& Agribusiness Marketing, 31(3), 237-254. https://doi.org/10.1080/08974 438.2018.1520176

Gross, J. J. (1998). The Emerging Field of Emotion Regulation: An Integrative Review. Review of Psychology, 2(3), 271-299. https:// doi.org/10.1037/1089-2680.2.3.271

Hackley, C. (1999). Tacit Knowledge and the Epistemology of Expertise in Strategic Marketing Management. European Journal of Marketing, 33(7/8), 720-735. https://doi. org/10.1108/03090569910274348

Hackley, C. (2000). Silent Running: Tacit, Discursive and Sociological Aspects of Management in a Top UK Advertising Agency. British Journal of Management, 11(3), 239-254. https://doi.org/10.1111/1467-8551.00164

Hackley, C. (2003a). 'We are All Customers Now...' Rhetorical Strategy and Ideological Control in Marketing Management Texts. Journal of Management Studies, 40(5), 13251352. https://doi.org/10.1111/1467-6486.00382

Hackley, C. (2003b). How Divergent Beliefs Cause Account Team Conflict. International Journal of Advertising, 22(3), 313-332. https:// doi.org/10.1080/02650487.2003.11072856

Hackley, C. (2009). Marketing: A Critical Introduction. Thousand Oaks, CA: SAGE Publications. https://doi. org/10.4135/9781446288511

Hackley, C., \& Hackely, R. A. (2018). Advertising and Promotion (4th ed.). Thousand Oaks, CA: SAGE Publications.

Hamzelu, B., Gohary, A., Ghafoori, N. S., \& Heidarzadeh, H. K. (2017). Does Involvement Shapes Consumers' Response to Product Failure? Asia Pacific Journal of Marketing and Logistics, 29(2), 283-304. https://doi. org/10.1108/APJML-03-2016-0042

Heath, R., \& Feldwick, P. (2008). Fifty Years Using the Wrong Model of Advertising. International JournalofAdvertising, 50(1), 29-59. https://doi.org/10.1177/147078530805000105

Hornik, J., Ofir, C., \& Rachamin, M. (2016). Quantitative evaluation of persuasive appeals using comparative meta-analysis. The Communication Review, 19(3), 192-222. https://doi.org/10.1080/10714421.2016.1195204
Houston, M. J., \& Rothschild, M. L. (1978). Conceptual and Methodological Perspectives. On Involvement. Research frontiers in marketing: dialogues and directions, 184-187.

Josephson, S., Kelly, J., \& Smith, K. (2020). Handbook of Visual Communication: Theory, Methods, and Media. London: Routledge.

Kimmel, A. J. (2018). Psychology Foundations of Marketing: The Keys to Consumer Behavior (2nd ed.). New York, NY: Routledge.

Kotler, P., \& Armstrong, G. (2018). Principles of Marketing (17th ed.). Harlow: Pearson Education.

Kotler, P., \& Keller, K. L. (2016). Marketing Management (15th ed.). Harlow: Pearson Education.

Kover, A. J. (1995). Copywriters' Implicit Theories of Communication: an Exploration. Journal of Consumer Research, 21(4), 598611. https://doi.org/10.1086/209421

Laurent, G., \& Kapferer, J. N. (1985). Measuring Consumer Involvement Profiles. Journal of Marketing Research, 22(1), 41-53. https://doi.org/10.1177/002224378502200104

Lee, S., \& Heere, B. (2018). Exploring the Relative Effectiveness of Emotional, Rational, and Combination Advertising Appeals on Sport Consumer Behaviour. Sport Marketing Quarterly, 27(2), 82-92. https://doi. org/10.32731/SMQ.272.062018.02

Leiss, W., Kline, S., Jhally, S., \& Botterill, J. (2005). Social Communication in Advertising. Consumption in the Mediated Marketplace. London: Routledge.

Levens, M. (2012). Marketing: Defined, Explained, Applied (2nd ed.). London: Pearson Education.

Matušínská, K., \& Zapletalová, Š. (2021). Rational and Emotional Aspects of Consumer Behaviour. Forum Scientiae Oeconomia, 9(2), 95-110. https://doi.org/10.23762/FSO_VOL9_ NO2_5

Moriarty, S., Mitchell, N., Wood, C., \& Wells, W. (2019). Advertising \& IMC: Principles \& Practice. London: Pearson Education.

Pelsmacker, P. D., Geuens, M., \& Bergh, J. V. D. (2018). Marketing Communications: A European Perspective. Harlow: Pearson Education.

Percy, L., Rossiter, J. R., \& Elliott, R. (2001). Strategic Advertising Management. Oxford: Oxford University Press.

Petrů, N., Kramoliš, J., \& Stuchlík, P. (2020). Marketing Tools in the Era of Digitization and 
Their Use in Practice by Family and Other Business. E\&M Economics and Management, 23(1), 199-214. https://doi.org/10.15240/ tul/001/2020-1-014

Pourazad, N., Stocchi, L., \& Pare, V. (2019). Brand Attribute Associations, Emotional Consumer-Brand Relationship and Evaluation of Brand Extensions. Australasian Marketing Journal, 27(4), 249-260. https://doi. org/10.1016/j.ausmj.2019.07.004

Rossiter, J. R., Percy, L., \& Donovan, R. J. (1991). A better Advertising Planning Grid. Journal of Advertising Research, 31(5), 11-21.

Shan, G., \& Gerstenberger, S. (2017). Fisher's exact approach for post hoc analysis of a chi-squared test. PLOS ONE, 12(12), e0188709. https://doi.org/10.1371/journal. pone.0188709

Sharpe, D. (2015). Chi-Square Test is Statistically Significant: Now What? Practical Assessment, Research, and Evaluation, 20, 8. https://doi.org/10.7275/tbfa-x148

Smith, P. R., \& Zook, Z. (2012). Marketing Communications: Integrating Offline and Online with Social Media. London: KoganPage.

Svenson, S. (2007). Producing marketing: Towards a Social-Phenomenology of Marketing Work. Marketing Theory, 7(3), 271-290. https:// doi.org/10.1177/1470593107080346

Teichert, T., Hardeck, D., Liu, Y., \& Trivedi, R. (2018). How to Implement Informational and Emotional Appeals in Print Advertisements. Journal of Advertising Research, 58(3), 363379. https://doi.org/10.2501/JAR-2017-054

Vakratsas, D., \& Ambler, T. (1999). How Advertising Works: What Do We Really Know? Journal of Marketing, 63(1), 26-43. https://doi. org/10.2307/1251999
Valenti, A., Yildirim, G., Vanhuele, M., Srinivasan, S., \& Pauwels, K. (2020). Is the Hierarchy of Effects Dead or Alive? In Proceedings from the 49th Annual EMAC Conference, 26-29 May 2020, Budapest, Hungary. Retrieved February 20, 2021, from http://proceedings.emac-online.org/ index.cfm?eventid=2\&EMAC $\% 202020 \% 20$ Annual\%20Con

Vaughn, R. (1980). How Advertising Works: A Planning Model. Journal of Advertising Research, 20(5), 27-33.

Vaughn, R. (1986). How Advertising Works: A Planning Model Revisited. Journal of Advertising Research, 26(1), 57-63.

Vázquez, J. S. F., \& Álvarez-Delgado, R. C. (2019). The Interaction between Rational Arguments and Emotional Appeals in the Entrepreneurial Pitch. International Journal of Entrepreneurial Behaviour \& Research, 26(3), 503-520. https://doi.org/10.1108/ ijebr-06-2019-0334

Yaakoop, A. Y., Mahadi, N., Ariffin, Z. Z., \& Omar, S. S. (2018). Review of Hierarchy-ofEffects (HoE) Models and Higher Education Advertising in Malaysia. Journal of Social Sciences Research, 4(11), 212-219. https://doi. org/10.32861/jssr.411.354.363

Yssel, J. C. (1994). An Evaluation of Advertising Strategies Developed according to the FCB Grid and the Bendinger Formula (Doctoral dissertation). University of South Africa, Pretoria.

Yssel, J. C. (1996). Demonstrating the Superiority of the FCB Grid as a Tool for Students to Write Effective Advertising Strategy. Journal of Advertising Education, 1(1), 31-41. https://doi.org/10.1177/109804829600100106 